University of South Carolina

Scholar Commons

$6-2001$

\title{
Consumer Self-Confidence: Refinements in Conceptualization and Measurement
}

William O. Bearden

University of South Carolina - Columbia, bbearden@moore.sc.edu

David M. Hardesty

Randall L. Rose

University of South Carolina - Columbia, roser@moore.sc.edu

Follow this and additional works at: https://scholarcommons.sc.edu/mark_facpub

Part of the Marketing Commons

Publication Info

Journal of Consumer Research, Volume 28, Issue 1, 2001, pages 121-134.

http://jcr.wisc.edu/

(C) 2001 by Journal of Consumer Research, Inc.

This Article is brought to you by the Marketing Department at Scholar Commons. It has been accepted for inclusion in Faculty Publications by an authorized administrator of Scholar Commons. For more information, please contact digres@mailbox.sc.edu. 


\title{
Consumer Self-Confidence: Refinements in Conceptualization and Measurement
}

\author{
WILLIAM O. BEARDEN \\ DAVID M. HARDESTY \\ RANDALL L. ROSE*
}

\begin{abstract}
The development and validation of measures to assess multiple dimensions of consumer self-confidence are described in this article. Scale-development procedures resulted in a six-factor correlated model made up of the following dimensions: information acquisition, consideration-set formation, personal outcomes, social outcomes, persuasion knowledge, and marketplace interfaces. A series of studies demonstrate the psychometric properties of the measures, their discriminant validity with respect to related constructs, their construct validity, and their ability to moderate relationships among other important consumer behavior variables.
\end{abstract}

$\mathrm{G}$ eneral self-confidence has been frequently cited as an important construct for understanding consumer behavior. For example, self-confidence has been hypothesized as an antecedent to subjective product knowledge (Park, Mothersbaugh, and Feick 1994), as a determinant of product-specific self-confidence (Locander and Hermann 1979), as a distinguishing characteristic of market-segment profiles (Darden and Ashton 1974), and as an influence on external search (Wells and Prensky 1996). Much of the extant consumer behavior research regarding the role of self-confidence has employed measures of self-esteem borrowed from psychology (e.g., Coopersmith 1967; Rosenberg 1965). Self-confidence issues (and the related self-esteem measures) have been studied principally from two perspectives in the marketing and consumer research literature: (1) laboratory experiments involving investigations of advertising and interpersonal influences and (2) field survey tests in which self-confidence is depicted as an antecedent of some marketing-related individual characteristic or knowledge attribute. Regarding the former, the use of self-esteem measures in studies of persuasion and group influence is based on the assumption that individ-

*William O. Bearden is the Bank of America Chaired Professor of Marketing at the University of South Carolina, the Darla Moore School of Business, Columbia, SC 29208 (bbearden@darla.badm.sc.edu); David M. Hardesty is assistant professor of marketing at the University of Miami, School of Business Administration, Coral Gables, FL 33124-6554; and Randall L. Rose is associate professor of marketing at the University of South Carolina, the Darla Moore School of Business, Columbia, SC 29208 (roser@darla.badm.sc.edu). The authors would like to thank the editor, the associate editor, and the three reviewers, as well as Rick Netemeyer, Terry Shimp, Kelly Tepper, and Stacy Wood, for their helpful comments and direction. uals high in self-esteem are more difficult to persuade than are low-self-esteem individuals.

Wood and Stagner (1994) suggest that the explanation for this assumption is twofold. First, high-self-esteem persons are thought to be more confident of their own judgments and consequently less influenced by others' opinions. Second, high-self-esteem individuals are more likely to believe others think well of them, and hence, are less concerned with social rejection than are low-self-esteem persons. Each of these explanations provides impetus for the use of selfesteem scales to reflect general feelings of self-confidence. However, and as explained below, the use of self-esteem measures to reflect consumer self-confidence has resulted in an equivocal pattern of effects. At least two reasons may account for these mixed results. First, self-esteem is a global personal trait that may have only limited correspondence with self-confidence as related to consumer and marketplace phenomena. Second, the dimensionality and validity of the most frequently employed measures have been questioned (Tomas and Oliver 1999). For example, the Janis and Field (1959) Feelings of Inadequacy (FIS) scale was originally developed to quantify a person's feelings of inadequacy, self-consciousness, and social anxiety. Questions about the dimensionality of the FIS and the low itemto-total correlations for some items in the scale have been raised (Fleming and Courtney 1984). The Rosenberg measure was originally designed to measure adolescents' global feelings of self-worth. The measure has been criticized for being susceptible to social desirability bias and for often being so skewed as to produce low tripartite-split groups that are still relatively high in self-esteem (Blascovich and Tomaka 1991). Moreover, questions regarding the dimensionality of the scale, as well as the presence of methods 
effects, have been raised (Tomas and Oliver 1999). Finally, Blascovich and Tomaka (1991) note that the Coopersmith (1967) Self-Esteem Inventory (SEI) measure, which was developed originally for use with children, is highly correlated with social desirability bias and lacks stable factor structure. Our premise, then, is that measures more closely tied to consumer phenomena may prove useful in efforts to investigate the role of confidence in the understanding of consumer behavior. As such, this effort is consistent with the frequently cited admonition of Kassarjian (1971) that consumer researchers need to develop measures more relevant to consumer issues.

The purpose, then, of this article is twofold. First, we offer a conceptual definition of consumer self-confidence, along with a description of the nomological network in which consumer self-confidence (CSC) is embedded and a brief discussion of related but different concepts. Our second objective is the development and validation of scales to measure the various dimensions that underlie consumer selfconfidence. We offer the measures as alternatives for use in the study of consumer-related phenomena, including both tests of consumer behavior theory and applied issues. Consumer self-confidence is important, too, both because it may serve as a protector against marketplace stress (Luce 1994) and because it provides motivation for consumers to seek assistance when confronted with complex or uncertain decisions. Moreover, the measures should prove useful as antecedents and moderators of relationships among other important consumer behavior constructs. Finally, we hope that our conceptualization and measures will enhance research that seeks to identify factors that increase or improve consumer self-confidence.

\section{CONSUMER SELF-CONFIDENCE AND RELATED CONCEPTS}

Consumer self-confidence is defined as the extent to which an individual feels capable and assured with respect to his or her marketplace decisions and behaviors. As such, consumer self-confidence reflects subjective evaluations of one's ability to generate positive experiences as a consumer in the marketplace (Adelman 1987). Consumer self-confidence is viewed as a multifaceted secondary disposition that is more closely related to consumer phenomena than are central dispositions such as self-esteem (Lastovicka 1982). Consumer self-confidence represents a relatively stable selfappraisal that is assumed to be readily accessible to the individual because of the pervasiveness of consumer activity in everyday life (Blascovich and Tomaka 1991).

Briefly, we propose that consumer self-confidence results from more basic traits, such as self-esteem, perceived control (Langer 1983), and dominance (Lorr 1991), and from the collection of the individual's prior marketplace experiences that are not independent of personal characteristics such as age, income, and education (Obermiller and Spangenberg 1998). While product-specific self-confidence will vary across product categories, feelings of global consumer self- confidence are still capable of differentiating among individuals within product-decision categories and purchase experiences. Moreover, like other consumer measures, general consumer self-confidence should be able to predict tendencies. For example, correlations with a summed index of specific self-confidence items assessed across a series of products would provide evidence of criterion validity (Obermiller and Spangenberg 1998). And, even in instances where the level of product- or situation-specific confidence may be low for most consumers, consumer self-confidence will still vary across individuals. In addition, purchase-specific factors, such as product expertise, can moderate the strength of the relationship between self-confidence and several outcomes. For example, greater expertise should strengthen the positive relationship between consumer selfconfidence and the exertion of influence on others and the negative relationships with persuasibility and perceived risk.

Consumer self-confidence is related to but differs from self-esteem, expertise, and product knowledge. Briefly, and considering each concept in turn, the concept of self-esteem goes by a variety of names (e.g., self-worth, self-respect, and self-acceptance), and it is assumed to represent the evaluative component of one's self-concept (Blascovich and Tomaka 1991). Self-esteem is the overall affective evaluation of one's own worth, value, or importance. As such, self-esteem is a broad concept, and confidence about one's abilities and performance in the marketplace may or may not be related to self-esteem. In general, high self-esteem should enhance consumer self-confidence, and thus self-esteem scales should have a modest, positive relationship with measures of consumer self-confidence.

Consumer expertise represents the individual's ability to perform product-related tasks successfully (Alba and Hutchinson 1987). Product expertise includes both the cognitive structure and the processes required to effectively use product information and beliefs stored in memory. As such, expertise, which typically increases as product-related experiences accumulate, reflects product-specific issues (Moorthy, Ratchford, and Talukdar 1997).

Consumer self-confidence is conceptualized as a multidimensional concept consisting initially of two higher-order factors, each made up of multiple dimensions (Gerbing, Hamilton, and Freeman 1994). These multiple dimensions, which define specific domains of content, are subsequently operationalized using a unidimensional set of individual items. The two higher-order factors represent the two major functions served by enhanced consumer self-confidence (Mossman and Ziller 1968). That is, consumer self-confidence reflects the individual's perceived ability (1) to make effective consumer decisions, including the ability to acquire and use information (DM); and (2) to protect himself or herself from being misled, deceived, or treated unfairly (PROT). Consumer self-confidence, then, functions to enable the consumer to operate effectively when faced with complex decisions involving large amounts of information and strain from marketplace pressures. The behaviors of persons low in consumer self-confidence are more subject 
to environmental circumstances and are more inclined to inconsistent decision-making than are those of persons who are high in consumer self-confidence (Mossman and Ziller 1968). However, overconfidence can also undermine the quality of consumer decision making (Alba and Hutchinson 2000).

The two higher-order constructs also represent important streams of research in the consumer behavior literature, both of which deal with the individual's ability to operate effectively in the marketplace. First, the decision-making component is consistent with the extensive body of consumer research that has attempted to understand and improve consumer performance through knowledge of how marketplace information is obtained, analyzed, and used to make purchase-related decisions (Bettman, Johnson, and Payne 1991; Nedungadi 1990). Moreover, this component is consistent with many of the descriptions embodied in general models of consumer behavior. The second higher-order factor corresponds to the ability of the consumer to operate effectively in the exchange process, the basic unit in most consumer behavior analysis (Oliver 1997; Richins 1983). These two higher-order factors are also consistent with the most frequently studied roles of consumer self-confidence in the consumer behavior and marketing literature. For example, Park et al. (1994) and Wright (1975) propose that self-confidence operates as an antecedent to marketplace choices and subjective knowledge perceptions. Likewise, Luce (1994) and others relate self-confidence to the individual's ability to protect himself or herself from harm under emotional strain and to resist persuasive attempts emanating from others in the marketplace.

\section{Decision-Making Self-Confidence}

Information Acquisition and Processing (IA and IP). Two subdimensions reflect the individual's confidence in his or her ability to obtain needed marketplace information and to process and understand that information (Moorthy et al. 1997; Punj and Staelin 1983). While consumers' need for information varies across product categories and with experience, the ability to acquire and process the right amount and content of information prior to further decision making is an important antecedent to effective decision making (Alba and Hutchinson 1987). Moreover, differing levels of confidence in information acquisition and processing capabilities may well explain some of the variance in prepurchase information-search activity that occurs even for high-ticket durable goods (Moorthy et al. 1997).

Consideration-Set Formation (CSF). The third dimension represents confidence in one's ability to identify acceptable choice alternatives, including products, brands, and shopping venues. This dimension is consistent with the frequently used heuristic in which consumers screen the large number of alternatives (e.g., brands) available to arrive at a more manageable and relevant set, frequently labeled the consideration set (Hauser and Wernerfelt 1990). Moreover, this definition and label recognizes that consumers may well form consideration sets that include alternatives from diverse categories (Nedungadi 1990). For many decisions, a large variety of alternatives are generally available, both within and across decision categories, that satisfy the same consumption or purchase objective. Like Ratneshwar, Pechmann, and Shocker (1996), we are assuming that consideration sets are frequently constructed as part of consumers' problem-solving routines. Moreover, the assumption is made that individuals vary in confidence regarding their ability to construct consideration sets that contain choice alternatives for effectively satisfying consumption goals. Concern for one's ability to develop or identify meaningful consideration sets is consistent with a number of basic theories and results in behavioral science (Hauser and Wernerfelt 1990). For example, Wright (1975) argues that consumers often strive to simplify their decision environment, while Alba and Hutchinson (1987) describe several phenomena related to simplification of choice through consideration-set formation.

Personal and Social Outcomes (PO and SO) The fourth and fifth dimensions of the decision-making higherorder factor are labeled personal outcomes and social outcomes, respectively. Through these dimensions, it is recognized that consumers must make decisions routinely regarding the choice and purchase of products and services (Bettman et al. 1991) and that these decisions result in outcomes that elicit personal feelings of satisfaction and, in many situations, reactions from others. More formally, these aspects of consumer self-confidence are defined as the confidence in one's ability to meet purchase objectives such that choices are personally satisfying and generate positive outcomes in the form of the reactions of others (including friends, family, and neighbors; Wright 1975). As such, these subdimensions of consumer self-confidence reflect the individual's beliefs regarding his or her ability to make sound judgments and to draw effectively on prior experiences and learning in efforts to arrive at satisfactory decisions.

\section{Protection}

Persuasion Knowledge (PK). The persuasion knowledge dimension reflects the individual's confidence in his or her knowledge regarding the tactics used by marketers in efforts to persuade consumers (Friestad and Wright 1994). This dimension of consumer self-confidence reflects the individual's confidence in his or her ability to understand marketers' tactics and to cope with these tactics. As such, this dimension recognizes that consumer self-confidence includes one's perceived ability to understand the cause and effect relationships that determine marketers' behavior and to deal with these attempts to persuade.

Marketplace Interfaces (MI). The remaining facet of consumer self-confidence reflects confidence in the ability to stand up for one's rights and to express one's opinion when dealing with others in the marketplace (e.g., store employees and salespersons). Persons high in consumer selfconfidence are more likely to express their own positions 
and to deal forthrightly with store clerks and other marketing boundary personnel than are persons who are low in consumer self-confidence. Consequently, consumers scoring high on this dimension should possess greater assurance in their own ability to interact with others in exchange situations, including requests for product demonstrations, refusals to purchase, and demands to remedy defective products (Richins 1983).

\section{OVERVIEW}

The research reported in the remainder of this article involves the development and validation of multiple measures for the dimensions of consumer self-confidence. First, we describe the procedures used to generate and purify our initial pool of items. We provide evidence from these procedures for the content validity of the items. We then use data from study $1(n=221)$ and study $2(n=204)$ to select items based on corrected item-to-total correlations and factor analysis loadings. Subsequently we use confirmatory factor analyses on data obtained in study $3(n=252)$ to examine factor structure, as well as to provide evidence of dimensionality, scale reliability, and discriminant validity. Then, we provide evidence of construct validation by examining the relationships between the confidence scales developed here, several competing measures, and a series of theoretically related consequences. Specifically, we report further evidence from a series of analyses using data from studies 1 and 2 and from additional studies we have carried out. The first of these additional studies, study $4(n=59)$, provides evidence of test-retest reliability, as well as of convergent and predictive validity. In study $5(n=60)$, we examine the convergent validity of the measures using data from husband-wife pairs. Next, we offer evidence of known group validity from study $6(n=100)$. Finally, we present the results of study $7(n=106)$, which was designed to test theoretical predictions regarding the relationships among self-confidence, the strength of price-quality schema, and consumer choices.

\section{ITEM GENERATION AND CONTENT VALIDITY}

An initial pool of 145 items was generated from exploratory interviews with adult consumers and a review of items used in earlier studies. In the exploratory interviews, a convenience sample of 43 adult consumers of mixed age ( $M=34.2$ years) and gender ( 23 females) was asked to provide descriptive statements of individuals both high and low in the dimensions of consumer self-confidence following exposure to the definitions for each dimension. Frequently mentioned statements from the open-ended descriptions were converted to statements and included in the initial item pool (Richins and Dawson 1992). In addition, items addressing related concepts were adapted from measures used by Allison (1978), Luce (1994), Lumpkin (1985), Oliver and Bearden (1985), Richins (1983), Wells and Tigert (1971), Wilkes (1992), and Wright (1975). Following de- velopment of this initial set of statements, item screening to eliminate redundant, double-barrel, ambiguous, and leading statements reduced the pool of items to 116 statements.

Fourteen marketing faculty members were then used to judge the remaining items. These expert judges were asked to rate how well each of the remaining items reflected the different dimensions of self-confidence, using the following scale: 1 = clearly representative, 2 = somewhat representative, and $3=$ not representative at all (Zaichkowsky 1985). Each item was evaluated by seven judges with two sets of judges exposed to the items from either three or four of the seven dimensions. Only items evaluated as being on average as at least somewhat representative were retained. This process reduced the number of items to 97 . The number of items remaining per facet ranged from 11 for consideration-set formation to 20 for marketplace interfaces. In all the remaining studies, participants were asked to rate the extent to which each of the scale items was characteristic of them on a five-point scale labeled: $1=$ extremely uncharacteristic, $2=$ somewhat uncharacteristic, $3=$ uncertain, $4=$ somewhat characteristic, and $5=$ extremely characteristic.

\section{STUDIES 1 AND 2: ITEM PURIFICATION}

\section{Methods}

The remaining 97 items were administered to two samples of 221 and 204 nonstudent adults. The data were collected by student interviewers from two marketing research classes, and participants received course credit for their participation. Guidelines for respondent eligibility were provided to insure a varied sample and to exclude participation by family members and other students (Mick 1996). Interviewers were required to obtain responses from both genders and to interview one person from each of four age groups: 21-30, 31-40, 41-50, and above 50 .

The surveys were accompanied by a cover letter that explained the purpose of the research and provided instructions regarding how to respond using the required response format. The respondents' first names and telephone numbers were also obtained at the end of each survey, and for a subsample of the respondents these were successfully used to verify that the interviews were conducted properly and to check for response consistency. In each of these followup calls, the respondents verified their participation and the seriousness of their involvement with the research. The percentages of female respondents were 51 and 46 for study 1 and study 2 , respectively. For both studies, the median age category was $31-40$ years, with 40 percent of both samples being over age 40 .

\section{Item Analyses}

Items were first evaluated for each facet using principalaxis factor analysis and an examination of corrected itemto-total correlations and item intercorrelations. Prior to these analyses, Kaiser-Meyer-Olkin tests of sampling adequacy 
TABLE 1

CONSUMER SELF-CONFIDENCE SCALE ITEMS

\begin{tabular}{|c|c|}
\hline Factor item & Factor loading \\
\hline \multicolumn{2}{|l|}{ Information Acquisition (IA): } \\
\hline I know where to find the information I need prior to making a purchase & .80 \\
\hline I know where to look to find the product information I need & .82 \\
\hline I am confident in my ability to research important purchases & .62 \\
\hline I know the right questions to ask when shopping & .60 \\
\hline I have the skills required to obtain needed information before making important purchases & .64 \\
\hline \multicolumn{2}{|l|}{ Consideration-Set Formation (CSF): } \\
\hline I am confident in my ability to recognize a brand worth considering & .85 \\
\hline I can tell which brands meet my expectations & .64 \\
\hline I trust my own judgment when deciding which brands to consider & .72 \\
\hline I know which stores to shop & .55 \\
\hline I can focus easily on a few good brands when making a decision & .60 \\
\hline \multicolumn{2}{|l|}{ Personal Outcomes Decision Making (PO): } \\
\hline I often have doubts about the purchase decisions I make & .81 \\
\hline I frequently agonize over what to buy & .67 \\
\hline I often wonder if I've made the right purchase selection & .73 \\
\hline I never seem to buy the right thing for me & .50 \\
\hline Too often the things I buy are not satisfying & .65 \\
\hline \multicolumn{2}{|l|}{ Social Outcomes Decision Making (SO): } \\
\hline My friends are impressed with my ability to make satisfying purchases & .89 \\
\hline I impress people with the purchases I make & .89 \\
\hline My neighbors admire my decorating ability & .53 \\
\hline I have the ability to give good presents & .53 \\
\hline I get compliments from others on my purchase decisions & .68 \\
\hline \multicolumn{2}{|l|}{ Persuasion Knowledge (PK): } \\
\hline I know when an offer is "too good to be true" & .70 \\
\hline I can tell when an offer has strings attached & .73 \\
\hline I have no trouble understanding the bargaining tactics used by salespersons & 62 \\
\hline I know when a marketer is pressuring me to buy & 68 \\
\hline I can see through sales gimmicks used to get consumers to buy & .74 \\
\hline I can separate fact from fantasy in advertising & .61 \\
\hline \multicolumn{2}{|l|}{ Marketplace Interfaces (MI): } \\
\hline I am afraid to "ask to speak to the manager" & .79 \\
\hline I don't like to tell a salesperson something is wrong in the store & .79 \\
\hline I have a hard time saying no to a salesperson & .59 \\
\hline I am too timid when problems arise while shopping & .67 \\
\hline I am hesitant to complain when shopping & .77 \\
\hline
\end{tabular}

and Bartlett tests of sphericity indicated that the data were appropriate for factor analysis. The two samples and seven sets of items resulted in 14 different analyses. Statistical criteria for item retention were $(a)$ an average (i.e., across the two samples) corrected item-to-total correlation above 0.35 , (b) an average interitem correlation above 0.20 , and (c) an average factor loading above 0.50 . Items were also considered for clarity of meaning and face validity regarding each item's relationship to the appropriate dimension. These analyses resulted in a remaining set of 39 items.

\section{STUDY 3}

\section{Confirmatory Factor Analysis}

In an effort to further evaluate the remaining items and their structure, a series of confirmatory factor models was examined using responses obtained from a third sample of 252 undergraduate business students. The models were es- timated using the covariance matrix as input via PROC CALIS (SAS Institute1989). Examination of item reliabilities, modification indices, and tests of discriminant validity from confirmatory factor analysis models for both a higherorder model and a seven-factor correlated model suggested that several items should be deleted and that the IP factor and its items cross-loaded with the information acquisition items and the consideration-set formation items. (These conclusions were subsequently supported by reanalysis of the study 1 and study 2 data using confirmatory factor analysis tests for the same two models.) These revisions then resulted in six factors and 31 items distributed as follows: IA (5 items), CSF ( 5 items), PO (5 items), SO (5 items), PK (6 items), and MI (5 items). The final set of confidence items is depicted in Table 1 along with their dimension labels and factor loadings from study 3 .

Subsequently, alternative factor structures were estimated. The models estimated were as follows: a null model; a onedimensional model for which all items were forced to load 
as indicators on a single factor; a two-factor uncorrelated model for which items loaded either on a single decisionmaking factor or a single protection factor; a similar twofactor correlated model; a six-factor orthogonal model; a six-factor first-order correlated model; and, a second-order factor model with two higher order factors, decision-making self-confidence (DM) and protection self-confidence (PROT), with four (IA, CSF, PO, and SO) and two subdimensions (PK and $\mathrm{MI}$ ).

As shown in Table 2, the two-factor higher-order model and the six-factor correlated model provided the best fit to the data when compared with the other models investigated. The chi-square values and degrees of freedom for the various models were as follows: the null model, $3,717.00,465 d f$, the one-factor model, 2,063.61, $434 d f$; the two-factor uncorrelated model, 2,003.80, $434 d f$; the two-factor correlated model, 1,886.28, $433 d f$; and the six-factor uncorrelated model, 1,055.68, $434 d f$. In contrast, fit statistics for the higher-order factor model were: chi-square, $767.58,427 d f$, $p<.01$; Tucker-Lewis Index (Non-Normed Fit Index; TLI or NNFI), 0.89; and Comparative Fixed Index (CFI), 0.90. The Root Mean Square Error of Approximation (RMSEA) for the higher order factor model was 0.06 . This latter statistic is less sensitive to distribution and sample size $(\mathrm{Hu}$ and Bentler 1998), and estimates within the 0.05 and 0.08 range indicate fair fit (Browne and Cudeck 1993). Overall, the six-factor correlated model resulted in a better approximation of the data. Specifically, the fit statistics were: chisquare, 742.54, $419 d f, p<.01$; TLI, 0.89; and CFI, 0.90 . The RMSEA for the six-factor correlated model was also 0.06 . While the chi-square statistic was significant, it was within the rule of 2.5 to 3 times the number of degrees of freedom suggested by Bollen (1989). The chi-square difference of $25.04(8 d f)$ between these latter two models was significant $(p<.01)$. The comparable chi-square difference tests for studies 1 and 2 were 64.55 and 28.25 . These results, then, suggest that a six-factor correlated model provides the best representation of the data.

\section{Scale Reliability}

Coefficient alpha estimates of internal consistency reliability for each dimension based on the study 3 data were as follows: 0.82 , information acquisition; 0.80 , consideration-set formation; 0.80 , personal outcomes; 0.82 , social outcomes; 0.83 , persuasion knowledge; and 0.86 , marketplace interfaces. The corresponding construct reliability estimates (Fornell and Larcker 1981) based on the standardized loadings for the six-factor correlated model were 0.83 , information acquisition; 0.81 , consideration-set formation; 0.81 , personal outcomes; 0.84 , social outcomes; 0.88 , persuasion knowledge; and 0.85 , marketplace interfaces. In addition, all indicator $t$-values were significant $(p<.01)$. Similar estimates were obtained based on the data from studies 1 and 2. For example, the corresponding coefficient alpha estimates from study 1 were 0.82 , information acquisition; 0.80 , consideration-set formation; 0.78 , personal outcomes; 0.81 , social outcomes; 0.85 , persuasion knowledge; and 0.84 , marketplace interfaces.

\section{Discriminant Validity}

Evidence of discriminant validity was first provided from the test recommended by Fornell and Larcker (1981) in which the pairwise correlations between factors obtained from the six-factor correlated model were compared with the variance extracted estimates for the constructs making up each possible pair. Evidence of discriminant validity occurs when both variance extracted estimates exceed the square of the correlation between the factors making up each pair. The phi estimates reflecting the correlations between dimensions ranged from 0.17 for PO-SO to 0.66 for IA-PK

TABLE 2

MODEL FIT

\begin{tabular}{|c|c|c|c|}
\hline Model & Chi-square $^{a}$ & Degrees of freedom & Chi-square difference \\
\hline Null & $3,717.00$ & 465 & \\
\hline One-factor & $2,063.61$ & 434 & $1,653.39^{* \star}$ \\
\hline \multicolumn{4}{|l|}{ Two-factor } \\
\hline uncorrelated & $2,003.80$ & 434 & $59.81^{* *}$ \\
\hline Two-factor correlated & $1,886.28$ & 433 & $117.52^{* *}$ \\
\hline Six-factor uncorrelated & $1,055.68$ & 434 & $830.60^{* *}$ \\
\hline Two-factor higher-order & 767.58 & 427 & $288.10^{* *}$ \\
\hline \multirow[t]{2}{*}{ Six-factor correlated } & 742.54 & 419 & $25.04^{* *}$ \\
\hline & TLI (NNFI) & $\mathrm{CFI}^{\mathrm{C}}$ & IRMSEA $^{d}$ \\
\hline Two-factor higher-order & .89 & .90 & .06 \\
\hline Six-factor correlated & .89 & .90 & .06 \\
\hline
\end{tabular}

"The chi-square differences represent comparisons of the one-factor model versus the null model, the two-factor uncorrelated model versus the one-factor model, etc.

${ }^{\circ} \mathrm{TLI}(\mathrm{NNFI})=$ Tucker-Lewis Index (Non-Normed Fit Index)

${ }^{\circ} \mathrm{CFI}=$ Comparative Fit index.

${ }^{\mathrm{R}} \mathrm{RMSEA}=$ Root mean square error of approximation.

${ }^{* *} p<.01$. 
and averaged 0.39 . Discriminant validity for the scale measures was suggested from the results of all 15 comparisons. Moreover, chi-square difference tests, in which one- and two-factor models for each possible pair of measures are estimated, were also examined. In all cases, strong support for discriminant validity was provided by significant chisquare differences $(p<.01$; Anderson and Gerbing 1988). Finally, the correlation between each pair of dimensions, plus or minus two standard errors, did not include the value one.

\section{ADDITIONAL EVIDENCE FROM STUDIES 1 AND 2}

\section{Study 1}

As part of the first study, data were collected for Rosenberg's 10-item self-esteem scale and an eight-item measure of consumer susceptibility to normative interpersonal influence (SUSCEP; Bearden, Netemeyer, and Teel 1989). Individuals scoring high in the dimensions of consumer selfconfidence should be less susceptible to interpersonal consumer influence and score higher in self-esteem. The coefficient alpha estimates of internal consistency reliability for the self-esteem and normative influence scales were 0.86 and 0.93 , respectively.

To begin, susceptibility to normative consumer interpersonal influence was inversely related to four of the six consumer self-confidence measures as expected $(p<.05)$, including the persuasion knowledge and marketplace interfaces factors reflecting interactions with others in the marketplace. These significant correlations were as follows: IA, -0.17 ; PO, -0.27 ; PK, -0.34 ; and, MI, -0.23 . The remaining two correlations were not significant. The correlations between the two higher-order factors and the SUSCEP scale were $-0.17(p<.05)$ and $-0.34(p<.01)$ for $\mathrm{DM}$ and PROT, respectively. The significant $(p<.05)$ pairwise correlations between the Rosenberg self-esteem measure and the IA, CSF, PO, PK, and MI measures were 0.18 , $0.21,0.36,0.27$, and 0.29 , respectively. That is, with one exception, the social outcomes self-confidence factor, the individual dimensions were positively correlated $(p<.05)$ with self-esteem as predicted. The correlations between DM and PROT and the same self-esteem scale were $0.28(p<$ $.01)$ and $0.34(p<.01)$, respectively.

\section{Study 2}

Relationships with Other Measures. The data from study 2 made possible tests of relationships between the consumer self-confidence measures developed here and a number of other concepts. First, the 20-item state self-esteem scale (SSES; Bagozzi and Heatherton 1994), the 10-item information processing confidence scale (IPC) used by Wright (1975), and a measure of product-specific self-confidence were assessed, along with the Park et al. (1994) measure of subjective product knowledge. The subjective knowledge measure was operationalized using procedures similar to those reported earlier by Park et al. (1994) in their study in which the Rosenberg self-esteem measure was employed to represent self-confidence as an antecedent of subjective product knowledge. Subjective product knowledge was assessed using a summed index across five different products, and it employed the following response format: "Please rate your knowledge of the following products as compared to the average person: (1) one of the least knowledgeable . . . (7) one of the most knowledgeable" (Park et al. 1994). The products included were CD players, lawn care products, long distance telephone services, cold remedies, and televisions. Product-specific self-confidence wás measured using the sum of five items operationalized with the following instructions: "How confident would you be in your ability to choose the best buy from among alternatives available in the following product and service categories: (1) not at all confident. . . (7) very confident." The five product categories included were personal computers, legal services, exercise equipment, microwave ovens, and cellular telephones. Example items for SSES include "I am worried about whether I am regarded as a success or failure," and "I feel satisfied with the way my body looks right now." Example items from the IPC measure include "I have more trouble concentrating than most people," and "I am able to solve puzzles and riddles rapidly." The internal consistency estimates of reliability for SSES, IPC, product-specific self-confidence, and subjective product knowledge, were $0.89,0.73,0.69$, and 0.66 , respectively. The pairwise correlation between SSES and IPC was 0.57 $(p<.01)$.

The SSES and IPC measures, along with the current consumer self-confidence scales, were included in a series of regression analyses in which the subjective knowledge and product-specific self-confidence measures served as dependent variables. These tests provided additional evidence regarding relationships between the current consumer selfconfidence measures and previously hypothesized outcomes of consumer self-confidence, and they provided the opportunity to investigate the contribution to explained variance of the consumer self-confidence scales beyond that provided by SSES and IPC. To begin, multiple-regression equations were estimated in which SSES, IPC, and the six measures of consumer self-confidence served as independent variables. Reductions in explained variance for subjective product knowledge and product-specific self-confidence were examined as the predictor variables were dropped from equations in which either IPC or SSES was employed initially as one predictor paired with the confidence predictors. These analyses enabled the examination of relative contribution to explained variance (i.e., relative loss of explanation) as correlated explanatory variables were omitted from each regression equation (Neter, Wasserman, and Kutner 1996).

The results of these analyses indicated that the self-confidence scales contributed significantly in every instance $(p<.05)$ to explained variance for both the subjective knowledge and product-specific self-confidence measures. In addition, the extra sums-of-squares tests, which account 
for the differing number of predictors in the equations being compared, revealed that the incremental explained variance of the self-confidence predictors exceeded that contributed by either IPC or SSES. Moreover, the results were more pronounced in comparisons of the self-confidence scales with the IPC measure. As one example, the equation involving IPC $(\beta=0.25, p<.05)$ and the consumer self-confidence measures (significant $\beta$ : IA, $0.24 ; \mathrm{PO}, 0.17$, PO; and MI, $0.20[p<.05])$ in the prediction of product specific selfconfidence resulted in an adjusted $R$-squared of 0.25 ( $p<$ .01 ). The $F$-statistics associated with the reductions in explained variance when IPC and the consumer self-confidence measures were dropped alternatively from the equation were 7.49 and 20.55 , respectively. The corresponding reductions in adjusted $R$-squared when confidence measures or IPC were dropped from the equation were 0.10 and 0.04 , respectively. These results using the current measures support the previously unsupported hypothesis of Park et al. (1994) regarding the positive relationship between consumer self-confidence and subjective product knowledge. In addition, the results were stronger than those obtained using competing measures.

Impression Management Bias. Responses to Paulhus's (1993) 20-item impression management (IM) scale were also collected in study 2 . These data made possible tests of the extent to which the self-confidence measures were correlated with a measure of desirable responding (IM), as well as an investigation of whether IM moderated, suppressed, or inflated the relationships with the measures of product-specific confidence and subjective product knowledge (Mick 1996). The internal consistency estimate of reliability for the impression management scale was 0.81 . Of the six dimensions, only the information acquisition $(r=0.21, p<.01)$ and consideration-set formation $(r=$ $0.18, p<.01$ ) measures were correlated with the impression management scale. For the two higher-order measures, the correlations between DM and PROT and the IM measure were $0.20(p<.05)$ and $0.10(p>.10)$. The simple correlations between IM and the state self-esteem scale and Wright's IPC measure were both 0.08 .

Moderated regression tests and partial correlations were used to reanalyze the relationships between the current consumer self-confidence scales and both the product-specific confidence and subjective product knowledge measures. First, partial correlation tests revealed only very slight, but nonsignificant, attenuation of the strength of the correlations when IM was controlled for. Moderated regression analyses revealed that the tendency to provide desirable responses only affected the relationships involving the index of product-specific self-confidence and the IA, CSF, and MI measures (Mick 1996). The tests involving relationships with the subjective product knowledge measure were not significant. In all three cases, for those respondents scoring above the median on the impression management scale, the relationships between IA, CSF, and MI with product-specific self-confidence were stronger. However, for both the lowand high-impression-management groups, the correlations remained significant. The same pattern of results was observed for the relationship between SSES and both the subjective knowledge and product specific self-confidence variables, in that the correlations between SSES and the two outcome variables were enhanced for those respondents scoring above the median.

\section{STUDY 4: TEST-RETEST RELIABILITY, CONVERGENT VALIDITY, AND RELATIVE PREDICTIVE VALIDITY}

\section{Test-Retest Reliability and Convergent Validity}

Responses to the confidence items were collected on two occasions separated by two weeks from a sample of 59 undergraduate business students. Test-retest correlations for the six dimensions ranged from 0.60 to 0.84 . For the phase 1 responses, the intercorrelations among the factors averaged 0.36 and ranged from 0.16 for the PO-SO relationship to 0.54 for the IA-CSF intercorrelation. As part of the second phase of the test-retest study, simple self-rating scales for each of the six dimensions were also collected in an effort to investigate convergent validity (Bagozzi 1993). To measure these self-ratings, subjects were presented with a description of the six consumer self-confidence dimensions and then asked to indicate the extent to which they possessed the characteristic, using seven-point agree-disagree rating scales. The correlations between these simple self-rating scales and their respective consumer self-confidence dimension averaged 0.54 and were as follows: IA, 0.47; CSF, 0.58 ; PO, 0.53; SO, 0.64; PK, 0.62; and MI, 0.39. All of these correlations were significant, and thus they provide some evidence of convergent validity. In addition, the correlation of the single-item scale with each matching dimension was higher than the correlations with the other five dimensions.

\section{Relative Predictive Validity}

The subjective knowledge, product-specific self-confidence, and IPC measures were also included in study 4 $(n=59)$. The correlations between the IPC measure and product-specific self-confidence and subjective knowledge scales were $0.26(p<.05)$ and $0.27(p<.05)$, respectively. Correlations between the current consumer self-confidence measures and subjective product knowledge and productspecific self-confidence were compared with the correlations between IPC and the two outcome variables. These tests revealed that the current measures were as strongly correlated or more so in all cases except one. Moreover, four of the six scales were significantly more correlated $(p<.05$, one-tail test) than IPC with both the subjective knowledge and product-specific confidence variables.

\section{STUDY 5: CONVERGENT VALIDITY}

Study 5 was designed to further investigate the convergent validity of the consumer self-confidence measures. As such, 
data were collected from a convenience sample of 60 married couples, ranging in length of marriage from six months to 53 years ( $M=23.5$ years). The respondents were members of a large church group; donations were made to support the activities of their group as incentive for their participation. Self-report data for the consumer self-confidence measures were collected from each wife. Husbands provided convergence data by responding to the same items, but as they pertained to their wives.

The results from study 5 are summarized in Table 3. First, two-factor correlated models for each confidence dimension were estimated. The item responses for each spouse represented the two factors. Construct reliability estimates based on these two-factor models for the six dimensions for the wife data were IA, 0.80; CSF, 0.74; PO, 0.79; SO, 0.82; $\mathrm{PK}, 0.83$; and, MI, 0.83. Comparable construct reliability estimates based on the responses of the husbands regarding their wives' consumer self-confidence were $0.77,0.63,0.75$, $0.75,0.88$, and 0.78 , respectively. The intercorrelations among the six factors for the wife responses averaged 0.31 and ranged from 0.02 (SO-MI) to 0.65 (PK-CSF).

As shown in Table 3, the phi coefficients representing the convergent validity correlations between the husband and wife responses for the six dimensions averaged 0.41 and ranged from 0.24 for $\mathrm{PO}$ and $\mathrm{PK}$ to 0.63 for SO. All of these estimates were significant $(p<.05)$, providing evidence of convergent validity for the consumer self-confidence measures. In addition, and again using the procedures employed earlier by Bagozzi (1993), responses were also collected from the wives to a series of single-item overall measures reflecting each dimension as additional estimates of convergent validity. Using structural equation models with multiple indicators for the consumer self-confidence dimensions, the correlations between the single-item overall estimates and the multi-item self-confidence scales were IA, 0.29; CSF, 0.40; PO, 0.40; SO, 0.55; PK, 0.58; and, MI, 0.28 . All of these correlations were significant $(p<.05)$. In an additional test of convergent validity, the average variance extracted (AVE) estimates based on the wife responses were compared with the squared phi-coefficients reflecting the correlations between the husband-wife dyad responses. Five of the six AVE estimates exceeded 0.50; the single exception (0.44) involved the PK measure. In all six comparisons, the AVE estimates for the wife responses exceeded the square of the phi-coefficients (which ranged from 0.06 to 0.36 ). These results, then, suggest that the responses driven by the wife as respondent account for more variation in scale scores than the husband-wife dyad responses.

\section{STUDY 6: KNOWN GROUP DIFFERENCES}

In an effort to provide additional evidence of validity for the six measures of consumer self-confidence, mean scores were compared with a sample for which meaningful differences were expected to occur (Lastovicka et al. 1999). Specifically, data were collected by mail survey from 100 members of the American Council on Consumer Interests (ACCI). The initial mailing was to a random sample of 200
TABLE 3

\section{CONVERGENT VALIDITY ESTIMATES}

\begin{tabular}{|c|c|c|c|c|}
\hline \multirow{2}{*}{$\begin{array}{l}\text { Consumer self- } \\
\text { confidence }\end{array}$} & \multicolumn{2}{|c|}{$\begin{array}{l}\text { Reliability } \\
\text { estimates }\end{array}$} & \multicolumn{2}{|c|}{$\begin{array}{l}\text { Convergent } \\
\text { validity }\end{array}$} \\
\hline & Wife & Husband & Husband ${ }^{a}$ & Wife $^{b}$ \\
\hline Measures & & & & \\
\hline $\begin{array}{l}\text { Information Acquisition } \\
\text { Consideration-Set }\end{array}$ & .80 & .77 & $.55^{*}$ & $.29^{*}$ \\
\hline Formation & .74 & .63 & $.34^{*}$ & $.40^{*}$ \\
\hline Personal Outcomes & .79 & .75 & $.24^{*}$ & $.40^{*}$ \\
\hline $\begin{array}{l}\text { Social Outcomes } \\
\text { Persuasion }\end{array}$ & .82 & .75 & $63^{*}$ & $.55^{*}$ \\
\hline Knowledge & .83 & .88 & $.24^{*}$ & $.58^{*}$ \\
\hline Marketplace Interfaces & .83 & .78 & $.43^{*}$ & $.28^{*}$ \\
\hline
\end{tabular}

aThese values represent the phi coefficients between husband and wife responses.

'These values represent the correlation between single-item overall estimates of confidence for each dimension and the wife responses.

${ }^{*} p<.05$.

nonstudent members of ACCI. The mission of ACCI is to provide a forum for the exchange of information about consumer issues and family economics to improve the wellbeing of individuals, households, and families. It was expected that these individuals would score higher in consumer self-confidence than samples drawn from the population at large. The sample averaged 22.4 years of professional experience with consumer issues; 68 percent were female. The average age of the respondents was 50.2 years. In an effort to examine for nonresponse bias, mean scores across the six self-confidence dimensions for the last one-fourth of the respondents were compared with the balance of the sample (Armstrong and Overton 1977). No differences were observed in terms of average scores between late and early responses.

The estimates of internal consistency reliability ranged from 0.70 for the social outcomes dimension to 0.85 for marketplace interfaces. The intercorrelations among the six factors averaged 0.22 and ranged from 0.10 (PO-SO) to 0.49 (IA-CSF). Tests of mean differences between the ACCI known group sample and the two nonstudent samples from studies 1 and 2 resulted in significant $t$-values $(p<.01$, twotail) for 10 of the 12 comparisons (i.e., studies 1 and 2 vs. the comparison group of consumer specialists for the six confidence dimensions). For the significant comparisons, the average $t$-values were 5.85 and 6.83 for the study 1 and study 2 comparisons, respectively. The means for the DM higher-order factor were 83.72 and 78.32 for the ACCI and study 1 respondents $(t=6.45, p<.01)$. Corresponding sample means for the PROT factor were 49.08 and 44.96 $(t=6.45, p<.01)$. As such, these significant comparisons provide additional support for the validity of the consumer self-confidence measures. The single nonsignificant difference for both samples involved the social outcomes factor. This finding suggests that confidence in decision making involving the reactions of others to one's decisions does not 
differ based on consumer-related experiences even for consumer-issue specialists. Possibly confidence in the reaction of others to one's own decisions and behaviors is lower than the remaining aspects of consumer confidence. This premise is supported by examination of the dimension mean scores that reveal that the social outcomes dimension mean scores are consistently lower than the other dimension mean scores across samples of all types.

\section{STUDY 7: AN APPLICATION STUDY}

In an additional effort to provide evidence of validity, the confidence measures were examined in a final study. The objectives of this study were threefold. First, the study provided a vehicle for demonstrating appropriate uses of the consumer self-confidence measures in a theoretically and practically relevant context. Second, the study was intended to test theoretically interesting and provocative predictions regarding the relationships among self-confidence, the strength of consumer price-quality schema (PQ), and consumer choices. Third, the study provided a comparison of the ability of the current measures, self-esteem (Rosenberg 1965), IPC (Wright 1975), and single-item product-specific self-confidence measures to moderate the relationship between PQ schema and choice.

The key issue to be addressed in this study concerns the conditions that facilitate the use of a price-quality heuristic when making product choices. To examine this issue, we adopt a view that is consistent with the concept of the confident consumer as an efficient information processor. This position is consistent with Alba and Hutchinson's (1987) conceptualization of the efficiency dimension of consumer expertise. That is, reliance on a heuristic to make choices need not be viewed as lazy, uninvolved, uninformed, or uncertain decision making. Rather, it is entirely rational and efficient to rely on price when making product choices if the consumer is confident in his or her ability to make personally satisfying decisions in general and confident, specifically, that price is sufficiently diagnostic of quality. Likewise, it is reasonable for the consumer to avoid relying on price if he or she is confident and believes strongly that price is not related to quality.

In summary, confidence empowers the consumer to act on the basis of strongly held beliefs (Berger and Mitchell 1989). Thus, consumer self-confidence is expected to moderate the relationship between the strength of consumers' PQ schema and their choice of a higher-priced product (Dhar 1997). That is, confidence should increase the likelihood of choosing the higher-priced product in a choice set when PQ schema is strong and decrease the likelihood of choosing the higher-priced product when PQ schema is weak. However, not every facet of CSC should be an equally powerful moderator of the PQ-choice relationship. Any application of the CSC scale must be sensitive to the nuances of the dimensions of self-confidence embodied in the subscales. In this particular case, those facets related to decision-making confidence in general and, in particular, to confidence in one's ability to obtain satisfying personal outcomes on the basis of product choices, should significantly moderate the PQ-choice relationship. Confidence dimensions related to protection (e.g., marketplace interfaces) should be less relevant to a decision-making task involving the processing of simple product attribute information presented in a mock advertisement format.

\section{Method}

Data were collected from 106 university faculty and staff members employed by a large state university. Forty-six percent of the respondents were female; 40 percent were full-time faculty members. The median age category was $41-50$ years. In addition to responding to the consumer selfconfidence measures and related items (i.e., IPC and SE), survey participants reacted to two choice stimuli similar to those employed by Dhar (1997). Briefly, subjects were asked to imagine that they were thinking of making purchase decisions in two product categories. Using instructions employed by Dhar (1997), the alternatives were described as being on special sale and, as in real choice situations, the respondent had the option to not make a choice. The respondent was also told that in the event the decision was made to defer choice and look for other options, the alternatives shown might or might not be available later. The two product categories used were bookshelf speakers and answering machines. Except for the price adjustments, the product descriptions had been pretested previously and found to be equal in attractiveness (Dhar 1997). Each product was described on five attributes in addition to price. The unbranded speakers were priced at $\$ 199$ and $\$ 189$. The Panasonic and AT\&T answering machine options were priced at $\$ 37.95$ and $\$ 39.95$, respectively. Four-item scales similar to those employed by Lichtenstein, Ridgway, and Netemeyer (1993) were used to assess the strength of respondents' price-quality schema for the two product categories. The items were scored $1-7$, with higher numbers indicating stronger price-quality schema.

\section{Results}

The internal consistency reliability estimates for the six CSC dimensions ranged from 0.70 to 0.88 and averaged 0.78 . In addition, the four decision-making dimensions were combined into an overall measure. The overall scale reliability estimate adjusted for dimensionality (Nunnally 1978) for DM was 0.90 . The reliability estimates for IPC, SE, and the two PQ schema measures for answering machines and bookshelf speakers were $0.71,0.85,0.86$, and 0.90 , respectively.

The ability of the PO and overall DM self-confidence measures to moderate the PQ schema-choice relationship was evaluated by analyzing subjects' answering machine choices using logistic regression. Choice of the higher-priced option (i.e., $\$ 39.95$ for the answering machine) or another option served as the binary dependent variable. Three predictor variables were input into the initial logistic regression: the PQ schema measure, decision-making confidence (DM), 
and the interaction of $\mathrm{PQ}$ with DM. A significant interaction of PQ schema with DM ( $p=.059)$ was observed in the first model, as predicted. A procedure suggested by Aiken and West (1991) was used to interpret the interaction. This procedure requires the evaluation of simple regression slopes for fixed levels of the moderator variable, DM in this case, and is analogous to simple main-effect tests in ANOVA. Simple regression slopes were computed at three levels of DM: at the mean $\left(\mathrm{DM}_{\mathrm{M}}\right)$, two standard deviations above the mean $\left(\mathrm{DM}_{\mathrm{H}}\right)$, and two standard deviations below the mean $\left(\mathrm{DM}_{\mathrm{L}}\right)$. These simple regression slopes are given in Equations 1-3.

$$
\mathrm{DM}_{\mathrm{H}}: \text { Choice }=-6.3495+.2835 \mathrm{PQ}(p<.10) \text {. }
$$

$$
\mathrm{DM}_{\mathrm{M}}: \text { Choice }=-1.2674-.0069 \mathrm{PQ} \text { (N.S.). }
$$

$$
\mathrm{DM}_{\mathrm{L}}: \text { Choice }=3.8146-.2974 \mathrm{PQ}(p<.10) \text {. }
$$

A clear pattern emerges from this analysis. Specifically, a positive regression of choice on PQ is observed when DM is high, while a negative regression of choice on PQ is observed when DM is low. That is, the likelihood that confident subjects choose the higher-priced brand increases as the strength of PQ increases. In contrast, the opposite pattern was observed for less confident subjects. The significant interaction in the overall logistic regression indicates that the slopes of the regression lines at $\mathrm{DM}_{\mathrm{L}}$ and $\mathrm{DM}_{\mathrm{H}}$ are significantly different (Aiken and West 1991). These results are consistent with the expected moderating role of DM consumer self-confidence.

The tests were repeated using PO instead of the more general DM measure of consumer self-confidence. The expected interaction between PQ schema and consumer selfconfidence was also observed when the specific PO dimension was modeled $(p=.089)$. The simple regression slopes are given in Equations 4-6.

$$
\mathrm{PO}_{\mathrm{H}}: \text { Choice }=-5.1706+.1960 \mathrm{PQ}(p=.15) .
$$

$$
\mathrm{PO}_{\mathrm{M}}: \text { Choice }=-0.9863-.0259 \mathrm{PQ} \text { (N.S.). }
$$

$$
\mathrm{PO}_{\mathrm{L}}: \text { Choice }=3.1980-.2478 \mathrm{PQ}(p<.10) \text {. }
$$

Once again, the relationship between choice of the higherpriced brand and the strength of subjects' PQ schema was positive for confident subjects (although the difference between the slope and zero only approached significance in this case). Conversely, less confident subjects exhibited a negative relationship between PQ schema and choice of the higher priced brand. The significant interaction term in the overall logistic regression indicates that the slopes of these lines for higher and lower confidence are different.
Identical analyses were conducted on subjects' choices for the unbranded bookshelf speakers. The interaction of $\mathrm{PQ}$ and DM was again significant $(p<.10)$ with the same contrast in slopes observed for answering machine choices, positive when DM was higher and negative when DM was lower. However, the expected interaction of $\mathrm{PQ}$ and $\mathrm{PO}$ was not observed $(p=.34)$. Finally, these moderator tests were repeated using IPC and SE rather than DM and PO. None of these interactions with $\mathrm{PQ}$ schema was significant $(p>$ .10 ) for either bookshelf speakers or answering machines. Thus, expectations regarding the relative predictive validity of the consumer self-confidence scale were supported in this study. However, the observed effects were not strong and should, therefore, be interpreted with caution. It should be noted that the price differences between the higher-priced and lower-priced brands described in the study were rather small. Stronger effects might be obtained with more substantial price differences. Note also that subjects were given the option of deferring choice (i.e., of choosing neither brand; Dhar 1997). Thus, the current study represents a rather stern test of the consumer self-confidence measure's ability to moderate relationships between important consumer behavior constructs.

\section{DISCUSSION}

Evidence regarding the dimensionality, reliability, and validity of the consumer self-confidence measures was provided. This evidence included tests of known group validity, convergent validity, response bias, test-retest, and predictive validity, in addition to evidence of reliability and validity from item and factor analyses. Also, and consistent with prior research, the consumer self-confidence measures were found to be positively related to product-specific self-confidence, overall self-confidence, and subjective product knowledge. It is important to note that the results support previously hypothesized but unsupported relationships found in consumer research (e.g., Park et al. 1994) and are stronger than those found using competing measures, such as Rosenberg's (1965) self-esteem scale, Wright's (1975) information-processing confidence measure, and Bagozzi and Heatherton's (1994) state self-esteem scale.

In study 7 , evidence was provided regarding the use of the consumer self-confidence measures to moderate theoretically and practically important relationships. Specifically, the decision-making and personal outcomes aspects of consumer self-confidence were shown to moderate the relationship between price-quality schema (Lichtenstein et al. 1993) and the choice of higher-priced options. And again, the study offered additional evidence regarding the relative predictive ability of the current measures versus several competing measures (e.g., self-esteem).

Consumer self-confidence may also be related in predictable ways to other consumer-related phenomena, and these potential relationships offer additional suggestions for future research. For example, consumer self-confidence should be positively correlated with market mavenism and action orientation. That is, persons high in consumer self- 
confidence should be more willing to discuss their marketplace knowledge with others (i.e., market mavenism; Feick and Price 1987) and to take action when motivated (Bagozzi, Baumgartner, and Yi 1992). Likewise, Beatty and Talpade (1994) suggest that greater confidence increases the likelihood that individuals will exert influence on others. Thus, consumer self-confidence may be an important construct in the study of the flip side of social influence, namely, factors affecting the propensity of consumers to exert influence rather than the more frequently studied antecedents and moderators of susceptibility to influence.

Consumer self-confidence may also be an important moderator of consumer responses to common marketing practices. For example, the effectiveness of informational advertising appeals may largely depend on their ability to attract consumers' attention and to motivate consumers sufficiently to ensure comprehension of key ad claims. LowCSC consumers may avoid attending to information laden ads at all or they may be less motivated to process the ads than high CSC consumers. Similarly, some products require assembly or instruction in proper use. Consumer satisfaction judgments may be dependent on these critical experiences, such that low-CSC consumers find assembly required or instructions for use to be onerous and threatening, as opposed to high-CSC consumers who find such experiences to be interesting and challenging.

\section{Future Scale Refinement Issues}

Our decision to emphasize the specific subdimensions considered in the current research was based on the extant literature used to motivate our multidimensional conceptualization of consumer self-confidence and the need to balance research contribution with parsimony. However, in the development of our scale, other dimensions were considered for inclusion. For example, product use and disposition are sometimes included in published definitions of consumer behavior (Jacoby, Berning, and Dietvorst 1977). Exclusion of these particular potential aspects of self-confidence was based largely on the fact that they involve postpurchase phenomena. In addition, the need to further explore the potential for response bias remains an area of needed research. In particular, a caveat is in order regarding the fact that the IA and CSF dimensions of consumer self-confidence were correlated with Paulhus's (1993) Impression Management Scale. Future research should address self-deception as a source of measurement contamination or as a related trait. Moreover, future applications of the consumer self-confidence scales should consider measuring SDR as a means of identifying any response bias problems.

A number of avenues for additional measurement-related research are tenable. For example, similar to the differences between objective versus subjective measures of knowledge (Brucks 1985), consumer self-confidence could also be addressed as an objective evaluation of one's ability versus a subjective self-assessment. The possible adaptation of our scales to product-specific measures, like those used to assess product opinion leadership (Childers 1986), warrants con- sideration. Possible curvilinear effects of confidence on decision making also warrant attention. For example, the conditions under which extreme levels of consumer confidence may lead to suboptimal decision making offer an interesting area for additional research (Alba and Hutchinson 2000).

For situations where the direct measurement of consumer self-confidence may be infeasible because of cost or time constraints, it would also be useful to identify demographic variables that may serve as surrogates for self-confidence. That is, correlations between consumer self-confidence and some demographic variables may increase the practical utility of the self-confidence construct in much the same way that benefit segmentation is enhanced if benefit segments can also be described in terms of more readily obtainable demographics. With the exception of gender, links with consumer demographics were not explored directly. However, it is interesting to note that five of the six consumer selfconfidence measures were found to be positively correlated in study $1(p<.05)$ with a three-item measure of subjective perceptions of income status (Rossiter 1995).

Finally, interesting gender effects were observed in studies 1 and 2. Women reported somewhat greater confidence in social outcomes and consideration-set formation than did the men. The greater confidence in social outcomes may be due to the well-documented tendency of women to have a stronger communal psychological orientation than men have (Meyers-Levy 1988). Communion refers to the tendency of women to consider relationships with others to be of paramount importance. Given the importance of managing social outcomes to women, it is perhaps not surprising that their greater practice managing such outcomes should lead to greater confidence in those abilities. It is somewhat less clear why women would express greater confidence in their ability to form satisfying consideration sets. One possibility involves the tendency of women to process product information more elaborately and, therefore, to recall important product information more accurately (Meyers-Levy and Maheswaran 1991). That is, the ability to recall product information accurately may enhance women's confidence when choosing brands to consider purchasing.

\section{[Received January 1997. Revised August 2000. David Glen Mick served as editor, and Hans Baumgartner served as associate editor.]}

\section{REFERENCES}

Adelman, Pamela K. (1987), "Occupational Complexity, Control, and Personal Income: Their Relation to Psychological WellBeing in Men and Women," Journal of Applied Psychology, 72 (November), 529-537.

Aiken, Leona S. and Stephen G. West (1991), Multiple Regression: Testing and Interpreting Interactions, Newberry Park, CA: Sage.

Alba, Joseph W. and J. Wesley Hutchinson (1987), "Dimensions of Consumer Expertise," Journal of Consumer Research, 13 (March), 441-454.

- and J. Wesley Hutchinson (2000), "Knowledge Calibration: What Consumers Know and What They Think They 
Know," Journal of Consumer Research, 27 (September), 123-156.

Allison, Neil K. (1978), “A Psychometric Development of a Test for Consumer Alienation from the Marketplace," Journal of Marketing Research, 15 (November), 565-575.

Anderson, James C. and David W. Gerbing (1988), "Structural Equation Modeling in Practice: A Review and Recommended Two-Step Approach," Psychological Bulletin, 103 (November), 411-423.

Armstrong, J. Scott and Terry S. Overton (1977), "Estimating Nonresponse Bias in Mail Surveys," Journal of Marketing Research, 14 (August), 396-340.

Bagozzi, Richard P. (1993), "Assessing Construct Validity in Personality Research: Applications to Measures of Self-Esteem," Journal of Research in Personality, 27 (March), 49-87.

—. Hans Baumgartner, and Youjae Yi (1992), "State versus Action Orientation and the Theory of Reasoned Action: An Application to Coupon Usage," Journal of Consumer Research, 18 (March), 505-518.

- and Todd F. Heatherton (1994), "A General Approach to Representing Multifaceted Personality Constructs: Applications to State Self-Esteem," Structural Equation Modeling, 1 (1), 35-67.

Bearden, William O., Richard G. Netemeyer, and Jesse E. Teel (1989), "Measurement of Consumer Susceptibility to Interpersonal Influence," Journal of Consumer Research, 9 (March), 183-194.

Beatty, Sharon E. and Sali Talpade (1994), "Adolescent Influence in Family Decision Making: A Replication with Extension," Journal of Consumer Research, 21 (September), 332-341.

Berger, Ida E. and Andrew A. Mitchell (1989), "The Effect of Advertising on Attitude Accessibility, Attitude Confidence, and the Attitude-Behavior Relationship," Journal of Consumer Research, 16 (December), 269-279.

Bettman, James R., Eric J. Johnson, and John W. Payne (1991), "Consumer Decision-Making," in Handbook of Consumer Behavior, ed. Thomas S. Robertson and Harold H. Kassarjian. Englewood Cliffs, NJ: Prentice Hall, 54-80.

Blascovich, Jim and Joseph Tomaka (1991), "Measures of SelfEsteem," in Measures of Personality and Psychological Attitudes, ed. John P. Robinson, Phillip R. Shaver, and Lawrence S. Wrightsman, San Diego: Academic Press, 115-160.

Bollen, Kenneth A. (1989), Structural Equations with Latent Variables, New York: Wiley.

Browne, Michael W. and Robert A. Cudeck (1993), "Alternative Ways of Assessing Model Fit," in Testing Structural Equation Models, ed. Kenneth A. Bollen and J. Scott Long, Newbury Park, CA: Sage, 136-162.

Brucks, Merrie (1985), "The Effects of Product Class Knowledge on Information Search Behavior," Journal of Consumer Research, 12 (June), 1-16.

Childers, Terry L. (1986), "Assessment of the Psychometric Properties of an Opinion Leadership Scale," Journal of Marketing Research, 23 (May), 184-188.

Coopersmith, Stanley (1967), The Antecedents of Self-Esteem, San Francisco: Freeman.

Darden, William R. and Dub Ashton (1974), "Psychographic Profiles of Patronage Preference Groups," Journal of Retailing, 50 (Winter), 99-112.

Dhar, Ravi (1997), "Consumer Preference for a No-Choice Option," Journal of Consumer Research, 24 (September), 215-231.

Feick, Lawrence F. and Linda L. Price (1987), "The Market Maven:
A Diffuser of Marketplace Information," Journal of Marketing, 51 (January), 83-97.

Fleming, James S. and Barbara E. Courtney (1984), “The Dimensionality of Self-Esteem II: Hierarchical Facet Model for Revised Measurement Scales," Journal of Personality and Social Psychology, 46 (February), 404-421.

Fornell, Claes and David F. Larcker (1981), "Evaluating Structural Equation Models with Unobservable Variables and Measurement Error," Journal of Marketing Research, 18 (February), 39-50.

Friestad, Marian and Peter Wright (1994), "The Persuasion Knowledge Model: How People Cope with Persuasion Attempts," Journal of Consumer Research, 21 (June), 1-31.

Gerbing, David W., Janet G. Hamilton, and Elizabeth B. Freeman (1994), "A Large-Scale Second-Order Structural Equation Model of the Influence of Management Participation on Organizational Planning Benefits," Journal of Management, 20 (Winter), 859-885.

Hauser, John R. and Birger Wernerfelt (1990), “An Evaluation Cost Model of Consideration Sets," Journal of Consumer Research, 16 (March), 383-408.

Hu, Li-tze and Peter M. Bentler (1998), "Fit Indices in Covariance Structure Modeling: Sensitivity to Underparameterized Model Specification," Psychological Methods, 3 (December), 424-453.

Jacoby, Jacob, Carol K. Berning, and Thomas Dietvorst (1977), "What about Disposition?" Journal of Marketing, 41 (April), 22-28.

Janis, Irwing J. and Peter B. Field (1959), "Sex Differences and Factors Related to Persuasibility," in Personality and Persuasibility, ed. Carl I. Hovland and Irwing L. Janis, New Haven, CT: Yale University Press, 55-68.

Kassarjian, Harold H. (1971), "Personality and Consumer Behavior: A Review," Journal of Marketing Research, 8 (November), $409-418$.

Langer, Ellen J. (1983), The Psychology of Control, Beverly Hills, CA: Sage.

Lastovicka, John L. (1982), "On the Validation of Life Style Traits: A Review and Illustration," Journal of Marketing Research, 19 (February), 126-138.

- L Lance A. Bettencourt, Renee Shaw Hughner, and Ronald J. Kuntze (1999), "Lifestyle of the Tight and Frugal: Theory and Measurement," Journal of Consumer Research, 26 (June), 85-98.

Lichtenstein, Donald R., Nancy M. Ridgway, and Richard G. Netemeyer (1993), "Price Perceptions and Consumer Shopping Behavior: A Field Study," Journal of Marketing Research, 30 (May), 234-245.

Locander, William B. and Peter W. Hermann (1979), "The Effect of Self-Confidence and Anxiety on Information Seeking in Consumer Risk Reduction," Journal of Marketing Research, 16 (May), 268-74.

Lorr, Maurice (1991), "A Redefinition of Dominance," Personality and Individual Differences, 12 (9), 877-879.

Luce, Mary Frances (1994), "Emotion and Consumer Choice: An Analysis of the Causes and Consequences of Negative, TaskInduced Emotion in Consumer Decision Domains," unpublished dissertation, Department of Business Administration, Duke University, Durham, NC 27708.

Lumpkin, James R. (1985), "Shopping Orientation Segmentation of the Elderly Consumer," Journal of the Academy of Marketing Science, 13 (Spring), 271-289. 
Meyers-Levy, Joan (1988), "The Influence of Sex Roles on Judgment," Journal of Consumer Research, 14 (March), 522-530. - and Durairaj Maheswaran (1991), "Exploring Differences in Males' and Females' Processing Strategies," Journal of Consumer Research, 18 (June), 63-70.

Mick, David Glen (1996), "Are Studies of Dark Side Variables Confounded by Socially Desirable Responding: The Case of Materialism," Journal of Consumer Research, 23 (September), 106-119.

Moorthy, Sridhar, Brian T. Ratchford, and Debabrata Talukdar (1997), "Consumer Information Search Revisited: Theory and Empirical Analysis," Journal of Consumer Research, 23 (March), 263-277.

Mossman, Beal Monroe, III and Robert C. Ziller (1968), "SelfEsteem and Consistency of Social Behavior," Journal of Abnormal Psychology, 73 (4), 363-367.

Nedungadi, Prakash (1990), "Recall and Consumer Consideration Sets: Influencing Choice without Altering Brand Evaluations," Journal of Consumer Research, 17 (December), 263-276.

Neter, John, William Wasserman, and Michael H. Kutner (1996), Applied Linear Statistical Models: Regression, Analysis of Variance, and Experimental Designs, Burr Ridge, IL: Irwin.

Nunnally, Jum C. (1978), Psychometric Theory, New York: McGraw-Hill.

Obermiller, Carl and Eric R. Spangenberg (1998), "Development of a Scale to Measure Consumer Skepticism toward Advertising," Journal of Consumer Psychology, 7 (2), 159-186.

Oliver, Richard L. (1997), Satisfaction: A Behavioral Perspective on the Consumer, New York: McGraw-Hill. - and William O. Bearden (1985), "Crossover Effects in the Theory of Reasoned Action," Journal of Consumer Research, 12 (December), 324-340.

Park, C. Whan, David L. Mothersbaugh, and Lawrence Feick (1994), "Consumer Knowledge Assessment," Journal of Consumer Research, 21 (June), 71-82.

Paulhus, Delroy L. (1993), "The Balanced Inventory of Desirable Responding," Reference Manual, BIDR Version 6, Department of Psychology, University of British Columbia, Vancouver, Canada V6T 1 Z4.

Punj, Girish N. and Richard Staelin (1983), "A Model of Consumer
Information Search Behavior for New Automobiles," Journal of Consumer Research, 9 (March), 366-380.

Ratneshwar, S., Cornelia Pechmann, and Allan D. Shocker (1996), "Goal-Derived Categories and the Antecedents of Across-Category Consideration," Journal of Consumer Research, 23 (December), 240-250.

Richins, Marsha L. (1983), "An Analysis of Consumer Interaction Styles in the Marketplace," Journal of Consumer Research, 10 (June), 73-82.

- and Scott Dawson (1992), "A Consumer Values Orientation for Materialism and Its Measurement: Scale Development and Validation," Journal of Consumer Research, 19 (December), 303-316.

Rosenberg, Milton (1965), Society and the Adolescent Self-Image, Princeton, NJ: Princeton University Press.

Rossiter, John R. (1995), "Spending Power and the Subjective Discretionary Income (SDI) Scale," in Advances in Consumer Research, Vol. 22, ed. Frank R. Kardes and Mita Sujan, Provo, UT: Association for Consumer Research, 236-240.

SAS Institute (1989), SAS/STAT Users Guide, Version 6, 4th ed., Vol. 1, Cary, NC: SAS Institute.

Tomas, José M. and Amparo Oliver (1999), "Rosenberg's SelfEsteem Scale: Two Factors or Methods Effects," Structural Equation Modeling, 67 (1), 84-98.

Wells, William D. and David Prensky (1996), Consumer Behavior, New York: Wiley.

- and Douglas J. Tigert (1971), "Activities, Interests, and Opinions," Journal of Advertising Research, 11 (August), 27-35.

Wilkes, Robert E. (1992), "A Structural Modeling Approach to the Measurement and Meaning of Cognitive Age," Journal of Consumer Research, 19 (September), 292-301.

Wood, Wendy and Brian Stagner (1994), "Why Are Some People Easier to Influence than Others?" in Persuasion: Psychological Insights and Perspectives, ed. Sharon Shavitt and Timothy C. Brock, Boston: Allyn \& Bacon, 149-174.

Wright, Peter L. (1975), "Factors Affecting Cognitive Resistance to Advertising," Journal of Consumer Research, 2 (June), $1-9$.

Zaichkowsky, Judith Lynne (1985), "Measuring the Involvement Construct," Journal of Consumer Research, 12 (December), 341-352. 